\title{
THE PREVALENCE AND IMPORTANCE OF UNCINARIASIS AMONG APPARENTLY HEALTHY SOUTHERN-BRED WHITE MEN IN THE UNITED STATES ARMY *
}

\author{
WESTON P. CHAMBERJ.AIN, M.D. \\ JACKSON BARRACKS, LA.
}

Until very recently the prevalence of hookworm disease among soldiers who have always resided in the United States appears to have been very little investigated. The only mention of uncinariasis in the report of the Surgeon-General of the Army for 1908 is that an examination of the stools of 21 soldiers at Fort Root, who had recently returned from the Philippine Islands, showed all to contain ova of Ankylostoma duodenale. In 1904 the surgeon at Fort Porter, New York, reported the presence of ankylostoma in many cases admitted to hospital for other conditions; but where the infection probably originated is not stated in the reference to his work. On Dec. 7, 1908, Captain J. F. Siler, of the Medical Corps of the Army, stationed at the large recruit depot of Fort Slocum, New York, reported to the Surgeon-General that of 19 southern recruits examined, 16, or 84 per cent., harbored ankylostoma. Of these, 3 were suspected of being so infected, while the remainder were in hospital for other reasons.

As a result of Dr. Siler's work, instructions were sent out for army surgeons to investigate the prevalence of uncinariasis among southernbred soldicrs. ${ }^{1}$ The result of my work on this subject illustrates how a well-known condition may be entirely overlooked until one's mind is specially directed to it. Prior to the present investigation, no case of uncinariasis had ever been recorded on the sick report at Jackson Barracks. During the three years I have been stationed there two cases were suspected of ankylostomiasis, but on examination both proved negative. Yet the result of my recent work is to show that 25 per cent. of the entire command harbored the hookworm, and that the condition had been

\footnotetext{
"Fead at the sixth annual meeting of the American Society of Tropical Medi. cine, held at the U. S. Naval Medical School, Washington, D. C., April 10, 1909.

1. By "southern-bred" is meant in this article men who were born and always had lived in some one of the following states: Maryland, Virginia, West Vircinia, North Carolina, South Carolina, Georgia, Florida, Alabama, Mississippi, Louisiana, Texas, Kentucky, Tennessee, Arkansas and Missouri.
} 
wholly unsuspected. It is undoubtedly true that similar mild infections are being constantly overlooked throughout the southern states as well as in the army.

\section{PERCENTAGE OF MEN INFECTED}

The work at Jackson Barracks has consisted of the examination of the blood and stools of $\mathbf{1 4} \%$ apparently healthy soldiers. For analysis these 147 cases are separated into four classes. The details are given in appended tables.

Class 1.-Newly enlisted southern-bred recruits received at the recruit depot at Jackson Barracks. There were 43 of these, and 29 were infected with uncinaria, a percentage of 67 (Table 1 ).

Class 2.- Southern-bred soldiers in the permanent command at Jackson Barracks serving in their first enlistment; that is, having three years or less in the army. Fifty-seven of these were examined and 31 were found infected, a percentage of 54. The average length of service for these men was 1.1 years, and only a single one of the positive cases had been in the army over two years (Table 2).

Class 3.- Southern-bred soldiers in the permanent command at Jackson Barracks who have served more than one enlistment; that is, over three years. There were 33 of these examined, and only 4 were found to have uncinariasis, a percentage of 11 . The average length of service for these men was 6.4 years. The four men infected had served, respectively, $4,5,61 / 2$ and 7 years. The number of worms found in these cases was small, the average being $5 \frac{1}{2}$ per man (Table 3 ).

Class 4.- Soldiers and recruits at Jackson Barracks who had liverl little or not at all in the south. Fourteen of these were examined, and no ova of uncinaria were found nor did the eosinophile count of any suggest the presence of intestinal parasites.

If the new recruits (Class 1) and the soldiers in their first enlistment (Class 2) are combined, we have 100 southern-bred soldiers with less than three years' service among them among whom an even 60 per cent. were infected with hookworms. Adding the 4 positive cases among the older soldiers, gives in all 64 cases of uncinariasis to be studied.

That this high percentage of uncinaria infections among southernbred recruits is probably the rule rather than the exception is shown by the following reports: Captain P. J. Owen, Medical Corps, U. S. A., stationed at Columbus Barracks, Ohio, records the finding of 8 cases of infection with Uncinaria americana among southern recruits, though how many were examined in all is not stated. Captain Siler has recently written me that he has now examined 140 recruits, finding over 85 per 


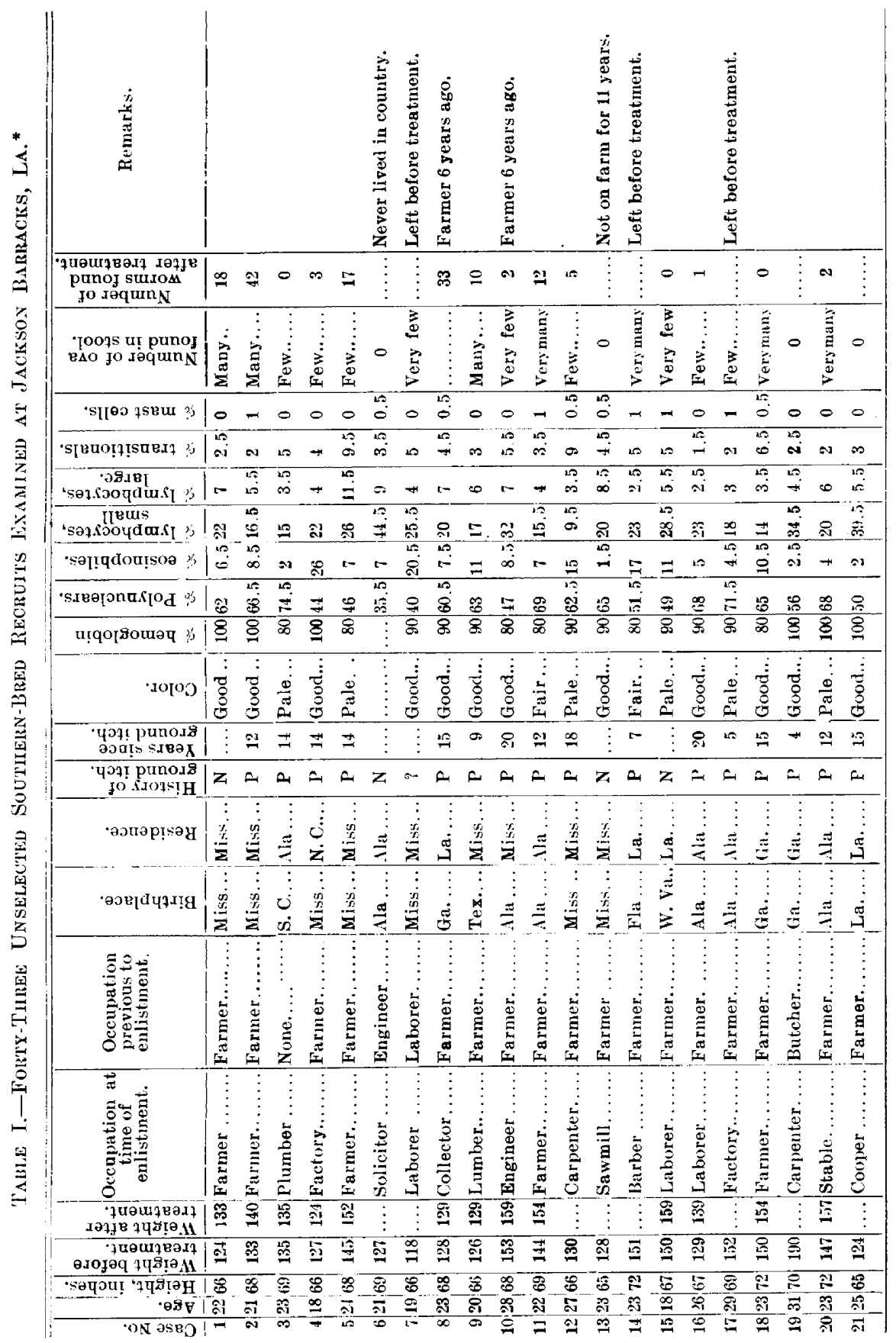




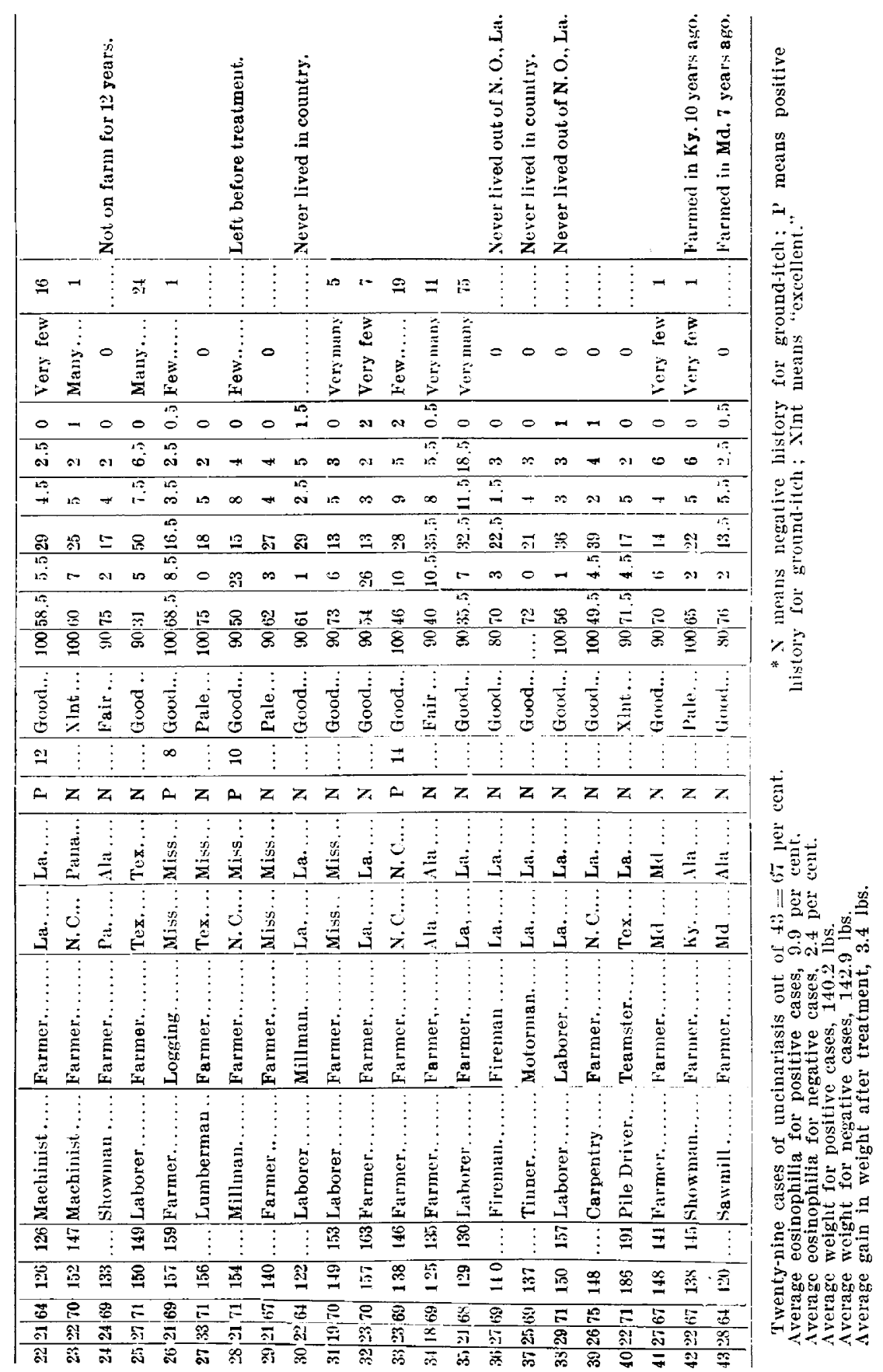




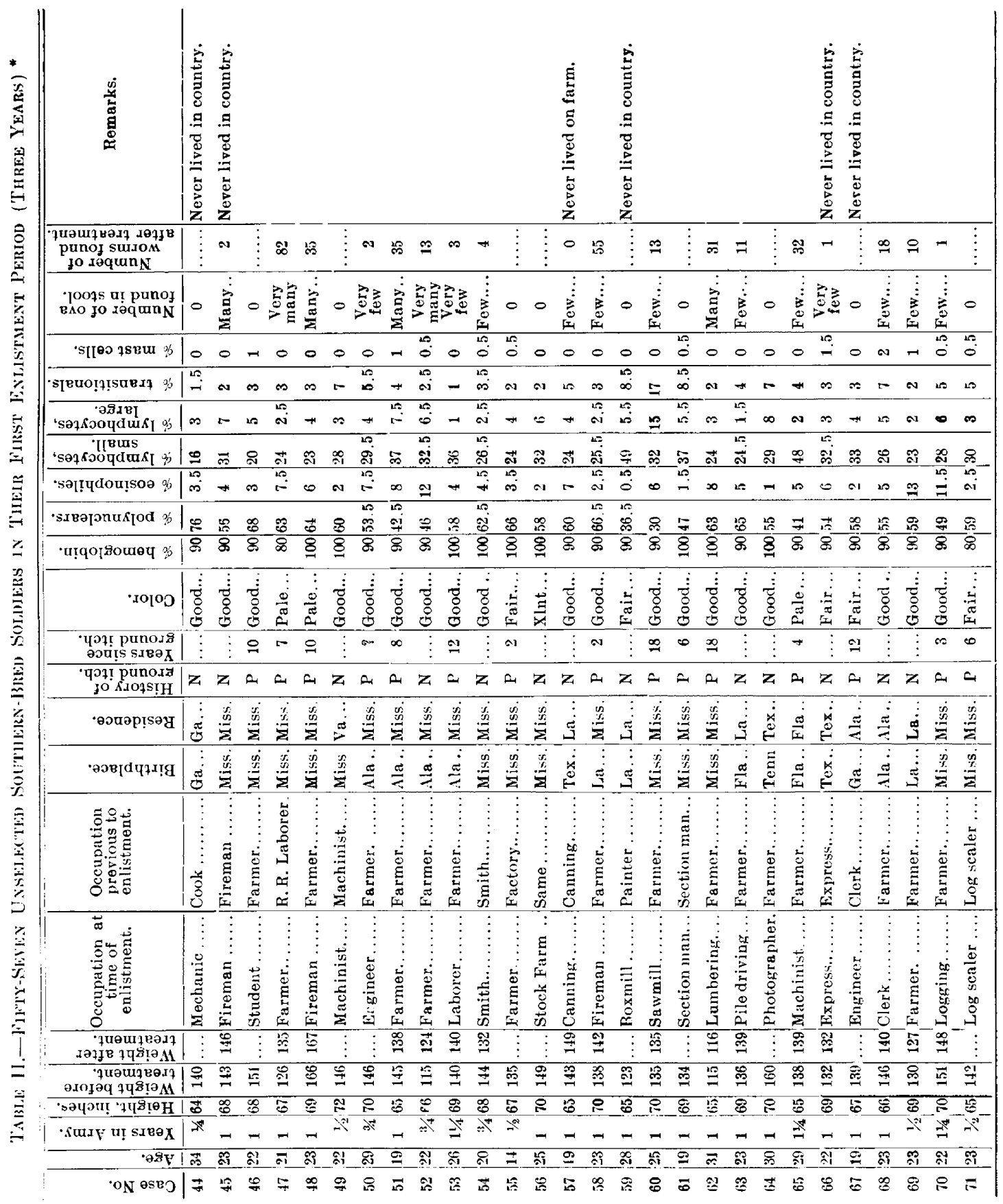




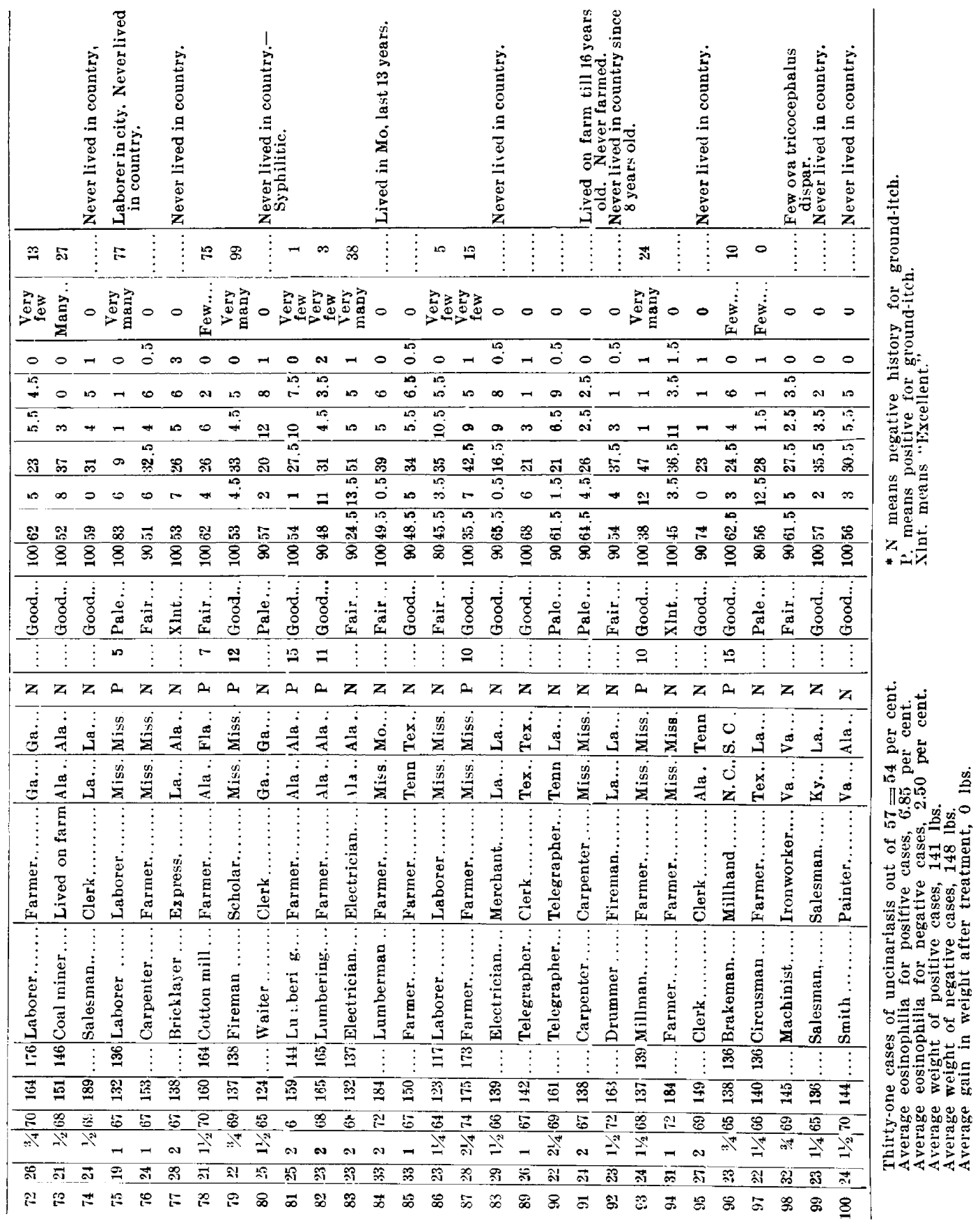


cent. infected. My own work in this direction was brought to an unexpected conclusion because of the sudden cessation of recruiting in New Orleans made necessary by reason of the fact that the army had nearly reached its authorized strength.

Strong reports ${ }^{2}$ that in an investigation of 4,106 Filipino prisoners 52 per cent. were found to be infected with uncinaria. If this can be taken as an index for the general population of the Philippines, it appears that the proportion of infections among the Filipinos, living in their insanitary manner, is not as high as that of southern-bred recruits who probably are less likely to be infected than the mass of the rural population of the south.

\section{CLINICAL SIGNS OF LIGH'T INFECTIONS}

First of all, it must be clearly understood that none of these infected subjects studied by me were sick. Many never had been on sick report, and, of those who had, only one presented symptoms which, in the light of positive uncinaria findings, could be attributed to the parasites. This patient had been in hospital several times with slight fever, indefinite intestinal symptoms and fleeting pains in chest and abdomen. He was unable to do any heavy work without soon becoming used up. Hemoglobin was 80 per cent. Seventy-seven worms were obtained after he was treated. With this exception, the cases I am reporting belong to the class of which Stiles says: "Under light infections may be included those patients who show eggs in the feces on microscopic examination, but who do not exhibit any or sufficiently marked symptoms to attract special attention. These cases are numerous and important, as they are capable of keeping a region infected and thus giving rise to severe cases. Hence from a prophylactic standpoint they should always be treated when found." That these cases can not be detected by mere inspection is evidenced by the words of Stiles, that "if these light cases were submitted to physical examination for enlistment in the army or navy, probably most of them would be accepted as sound."

As will be seen in the appended tables, I have classed the color of the men examined as "excellent," "good," "fair" or "pale." By "excellent" is meant the fresh, ruddy complexion so common among healthy northern men. It will be observed that very few of the southern men possessed this "excellent" color. Many are recorded as fair and a few as pale, but there

2. Strong (R. P.): Combating tropical diseases in the Philippines br scientific methods. Jour. Am. Med. Assn., 1909, lii, 524. 
seem to have been no notable differences in color between the positive and the negative cases.

In view of the great prevalence of uncinariasis in the South, it is thought that much caution must be used in looking on hookworms as the cause of atypical symptoms in a patient simply because the ova are found in the feces, since the presence of uncinaria in the intestines may be a mere coincidence.

Table III.-Four Cases of Uncinariasis Found Among Thibty-Three Unselected Southern-Bred Soldiers Who Have Served More Than One Enlistment Period (Over THREe Years) *

\begin{tabular}{|c|c|c|c|c|c|c|c|c|c|c|c|c|c|c|c|c|c|c|c|c|}
\hline 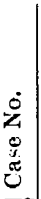 & 苾 & 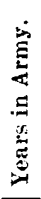 & 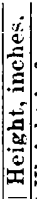 & 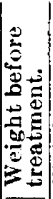 & 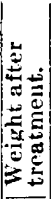 & 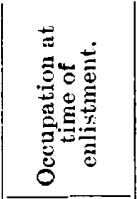 & 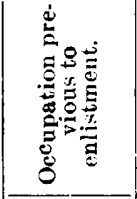 & 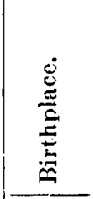 & 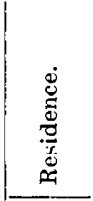 & 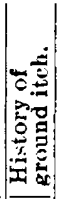 & $\stackrel{\stackrel{\Delta}{c}}{3}$ & 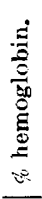 & 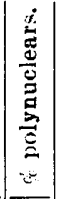 & 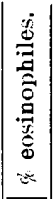 & 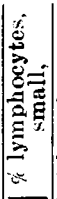 & 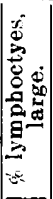 & 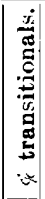 & 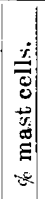 & 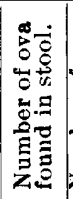 & 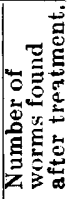 \\
\hline 109 & 26 & 4 & 68 & 156 & $14 \delta$ & Farmer... & Logging... & Tenn... & Tenn... & $\mathbf{N}$ & Good & 90 & 55 & 4 & 31 & 5 & 4 & 1 & Very & 2 \\
\hline 127 & 22 & 5 & 71 & 140 & 140 & Machinist. & Farmer. & N. C... & N. C.... & $\mathbf{N}$ & Fair. & 90 & 50 & 8 & 38 & 2 & 2 & 0 & Many & 11 \\
\hline 139 & 39 & $61 / 2$ & 68 & 145 & 140 & Salesman & Farmer.... & Mis.... & Miss... & $\mathbf{N}$ & Good & 90 & $5 \overline{5} . \tilde{5}$ & 10.5 & 24 & 4.5 & 5 & $|0.5|$ & Very & 6 \\
\hline 132 & 28 & 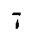 & 65 & 156 & 160 & Farmer. & Farmer. & Tenn... & Tenn... & $\mathbf{N}$ & Fair. & 90 & 31.5 & 26.5 & $36 .+4$ & 3 & & 0 & $\begin{array}{l}\text { Yery } \\
\text { few }\end{array}$ & 3 \\
\hline
\end{tabular}

* Twenty-nine negative cases are omitted from table as showing nothing of interest.

N. means negative for ground-itch.

Average eosinophilia 4 positive cases. 12.5

Average weight 4 positive cases $149.7 \mathrm{lbs}$

Average number of worms found, $51 / 2$.

\section{BLOOD APPEARANCES IN MILD INFECTIONS}

The reduction in hemoglobin in infected men was very slight, being less marked than was found in the cases reported by Siler. No case was found with the hemoglobin lower than 80 per cent; the majority showed 90 per cent. and a considerable number 100 per cent. Among the 133 southern-bred men the average hemoglobin percentage for the infected cases was 91.5 per cent, and for the non-infected 94.2 per cent., a difference of only 2.7 per cent. No counts of red cells were made.

The leucocyte count was made in 12 infected cases, but, as it did not secm to show anything of interest, it was discontinued. The highest count was $12, \% 00$, the lowest $\%, 600$, and the average 9,600 per cubic millimeter.

A differential count of the white cells was made in all cases and demonstrated, as was to be expected, that eosinophilia was present in the majority of those harboring hookworms. In the 64 positive cases the lowest eosinophile count was 1 per cent. and the highest 26 per cent. Fourteen cases showed less than 5 per cent. of eosinophiles. The average cosinophile count for the 64 infected cases was 8.5 per cent., and for 83 
non-infected cases 2.2 per cent. In the 83 negative cases, only 9 subjects showed an eosinophile count over 5 per cent., and, of these, 2 were infected with Trichocephalus dispar, which doubtless caused the eosinophilia. From these observations it appears that an eosinophilia of over j per cent. is a very strong point in favor of infection with an intestinal parasite, but that one below 5 per cent. is of no value in exeluding infection with Necator americanus.

\section{THE PARASITES}

Of the 64 patients in whom ova of uncinaria were demonstrated in the feces, 4 left before treatment. The remaining 60 patients were treated in the usual manner with $4 \mathrm{gm}$. of thymol, and worms were recovered from the stools of 56 . The smallest number found was 1 , the largest 99 , and the arerage number per patient was 16 . Whether this represents the entire amount of infection is not yet known, as very few of the patients have been re-cxamined since treatment, and it is probable that some worms still remain in many of the patients. The majority of the men interrogated some weeks after treatment reported that they felt better than before; one did not feel so well, and a few noted no change, these last being patients from whom only 2 or 3 worms were obtained.

All of the parasites are believed to have been American hookworms. Specimens from half of the cases were sent to Dr. C. W. Stiles for identification, and he reports that all were Necator americanus.

In the examination of the entire $14 \%$ men, it was surprising to find the ova of other parasites in only 3 cases, all of the 3 being infections with Trichocephalus dispar.

\section{LONGEVITY OF THE HIOOKWORM IN TIIE INTESTINES}

The length of time the parasite will live in the intestines seems to be in doubt, but that it may sometimes be a period of several years appears probable from $m y$ findings. The habits of the soldier and the sanitary conditions at this and practically all other army posts are such that reinfection with uncinaria larve is not probable. In the new recruits examined, 67 per cent. of infection was found; in the soldiers in their first enlistment, 54 per cent., and in those in subsequent enlistments, 11 per cent. This apparently indicates that there is a tendency for the worms in the soldier's intestine to die out gradually. This tendency, however, is not always rapid, as is shown by the persistence of the infection in some cases even to the fourth, sixth and seventh years of service. 
DIAGNOSIS

In the cases like those covered by this report the general appearances and ordinary physical examination are of no diagnostic value. Diagnosis must rest solely on the microscopic findings. As stated above, an eosinophilia of over 5 per cent. is very suggestive, but one below that by no means excludes uncinariasis. In these light infections the finding of ora in the feces is often a tedious process. I made my examinations by mixing a bit of feces with water and covering with a seven-eighth-inch corerglass. In Tables 1, 2 and 3 I have recorded the number of eggs in the stools as "very few," "few," "many" and "very many." If two or more slides were gone over before a single egg was found, the record "very few" was made. If one or two ora were found in a slide, the record was "few." The tables show "very few" in 18 , or 28 per cent., of the 64 cases, which means that at least two slides were gone over before an ovum was found. In several cases six or eight slides were examined before the first egg was discovered.

In some cases the number of eggs found in the feces seemed to bear no relation to the number of worms passed after the first course of treatment.

\section{SOURCE OF INFECTION}

In this series of cases, the findings coincide with previous expericnce as to the importance of rural life as a predisposing cause of infection. Among the 64 infected subjects, 53 gave a history of having at some time worked on a southern farm. Of the 11 remaining subjects 3 were laborers, 2 firemen and 1, each, a plumber, country blacksmith. expressman, brakeman, clectrician and canning factory employé. Only 4 infected subjects reported never having lived in the country, and, of these, 1 was a laborer, 1 an expressman, 1 a locomotive engineer and 1 worked in a factory canning shrimps and oysters.

Among the 100 xecruits and soldiers in their first enlistment, $\mathrm{r}_{4} \mathrm{had}$ been farmers at some period of their lives, the percentage of uncinariasis among these being 81 per cent. 'This closely approximates the findings of some physicians who have asserted that in parts of the south 90 per cent. of the rural population is affected with hookworm disease.

Most of the men gave a history of having gone barefooted in childhood, and a little over half reported having had ground itch, but in most cases the last attack was stated to have been a great many years before, so it is doubtful if much importance can be attached to that feature in this series (Tables 1,2 and 3 ). 
RELATION OF UACINARIASIS TO THE PHYSICAT DEYLLOUSIENT OF RECRCITE

It is considered by many recruiting officers that the physical development of the southern applicants for enlistment is below that of northern mon, and it is known that a great number of southern men are rejected at the recruiting stations for poor physical development and weight under that required. The observations made by myself, as well as by other army surgeons, have given the impression that the southern recruits are poorly ieveloped and poorly nourished. Some statistics from the records of the examination of recruits at Jackson Barracks confirm these impressions, as indicated by Table 4 .

\begin{tabular}{|c|c|c|c|}
\hline \multirow{2}{*}{$\begin{array}{l}149 \text { recruits not boln in south. } \ldots \ldots \ldots \\
308 \text { recruits born in the south } \ldots \ldots\end{array}$} & $\begin{array}{l}\text { Average } \\
\text { Height. }\end{array}$ & $\begin{array}{l}\text { Average } \\
\text { Weight. }\end{array}$ & $\begin{array}{l}\text { Relation of Weight to } \\
\text { the Army Standard }\end{array}$ \\
\hline & $662 / 5$ & $141 \%$ & $\begin{array}{l}13 \text { lbs. above. } \\
21 / 3 \text { ibs. below. }\end{array}$ \\
\hline 70 southern-born farmer recruits & $681 / 6$ & & $21 / 6$ lbs below. \\
\hline 64 soldiers with uncinariasis. & $683 / 7$ & $1401 / 2$ & 31/2 lbs. below. \\
\hline
\end{tabular}

Siler considers it probable that the poor development of the southern recruit is due to uncinariasis. In this connection these words of Stiles are of interest: "If infection occurs before puberty, it is likely to retard development, both mental and physical." My own work shows that the average weight of the infected cases was lower than that of the noninfected southern soldiers, though the difference is not very marked among the new recruits.

TABLe V-Weight of INFECTEd aNd NoN-INFected Southers Recrutts

\begin{tabular}{lll} 
Average & & \\
Weight. & Difference \\
143 & \multicolumn{2}{c}{} \\
$140^{1 / 4}$ & $23 / 4$ & Ibs. \\
$1481 / 2$ & $61 / 2$ & lbs. \\
142 &
\end{tabular}

14 southern recruits not infected ................. 143

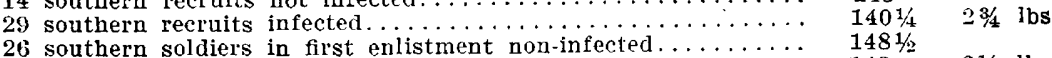

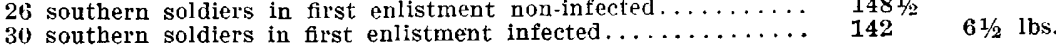

As seen in Table 4, the average weight of 64 infected soldiers, as compared with their height, was $3 \%$ pounds below the army standard, while the average for 149 northern-born recruits was 13 pounds above.

Whether the eradication of the parasites at the age of the average soldier will lead to an increase in weight is left in uncertainty by my observations. Siler reports a constant gain in weight in recruits after treatment. My 29 recruit patients, weighed about five weeks after treatment, showed an average gain of $31 / 2$ pounds. It is not fair, however, to attribute a gain of weight in recruits solely to the fact that they have been relieved of their hookworms, because it has been found that under ordinary circumstances recruits gain weight as a result of the regular life, good food, excellent sanitary conditions and graduated exercises associated with the military life. 
Among 34 seasoned soldiers, weighed on the average about one month after treatment, there was a total loss of 11 pounds, or about one-third of a pound per man. Some men gained markedly, while others lost as heavily. It is thought that further treatment of such as may be found still to harbor worms may show, if the patients be weighed one or two months later, after the effects of treatment have fully passed off, that eradication of the worms has farorably affected the weight.

\section{PROPIILAXIS}

It is probable that any applicant for enlistment in the army who has a marked infection with uncinaria will be detected by the ordinary examination given a recruit. The light infections which escape the examining officer apparently do not affect materially the efficiency of the soldier. and do not, in the patients' interest, urgently demand treatment. From the standpoint of prophylaxis, however, thorough treatment of the mild infections is of great importance both in the army and in civil life. It is probable that there are hundreds, perhaps thousands, of cases of mili uncinariasis in the army, some of which may be setting up new foci of infection in localities hitherto free from the disease. Just as the typhoid bacillus-carrier is a menace to the community, so is the hookworm-carrier, and the treatment of the comparatively few carriers in the military service and the countless ones outside the army will be one of the steps absolutely necessary if the disease in its severer manifestations is to be cradicated from the south.

\section{CONCLUSIONS}

1. Infection with uncinaria is very common among southern-bred soldiers during the first three years of service. In 100 men examined, 60 per cent. showed uncinariasis. Among new recruits the percentage of infections is at times as high as 85 .

2. Southern-bred soldiers with more than three years' service show a much lower percentage of infection, only 11 per cent. in 33 cases.

3. The worms gradually die out, most of them during the first three years, and under the favorable sanitary conditions obtaining in the army at home reinfection occurs rarely, if at all.

4. The symptoms produced by a light infection with hookworms are so slight that they can not be detected by the usual methods employed by the examining surgeon, and diagnosis must be made with the microscope. 
5. An eosinophile count of orer 5 per cent. is very strong evidence of infection with an intestinal parasite, but one below 5 per cent. is no evidence against uncinariasis.

6. The parasite in probably all cases is Necator americanus.

$\%$. In some cases the worm probably lives several years in the intestines.

8. In many light infections, the ova are difficult to find, requiring the complete examination of five or six cover-glass preparations.

9. Farm life is very important as a predisposing cause. Among $\because 1$ men who had farmed at some time, 81 per cent. were infected.

10. Most of the men had gone barefooted in childhood, and over half reported having had ground itch, though usually not since childhood.

11. Southern recruits are less well developed physically than northern ones.

12. Uncinariasis in childhood is a very probable cause of this underdevelopment.

13. Light infections do not materially affect the efficiency of the soldier, though the majority report that they feel more rigorous after treatment.

14. Treatment of the light infections is of great importance in any attempt to stamp ont the disease. 